\title{
Application of AHP-VIKOR and GMDH framework to develop an indicator to identify utilisation potential of wave energy converter with respect to location
}

\section{Tilottama Chakraborty*, Mrinmoy Majumder and Ankit Khare}

School of Hydro-Informatics Engineering,

National Institute of Technology,

Agartala, Tripura (W), India

Email: tilottama86@gmail.com

Email: mamjumder15@gmail.com

Email: ankitkhr007@gmail.com

*Corresponding author

\begin{abstract}
The potential of analytical hierarchy process (AHP)-rough number based compromise ranking method (also known as VIKOR) multi-criteria decision-making (MCDM) and group method of data handling (GMDH) multimodal predictive method was analysed for smart representation of 'utilisation potential' of wave energy converters from specific locations. The significant parameters were identified by considering different case studies and their influence on converter efficiency. The soft-computation methods like AHP-VIKOR and GMDH were used for the first time to find the relative priority values of the parameters. The results from the multi-method estimation model were validated with the help of multi linear regression equation and certain real-time case analysis. With an accuracy of above, $99 \%$ the ensemble MCDM-ANN model depicted reliability, which ensures the author of its wide application for real benefits like cost reduction and efficiency maximisation of converters in the utilisation of the potential wave energy of locations.
\end{abstract}

Keywords: analytical hierarchy process; AHP; VIKOR; group method of data handling; GMDH; ensemble modelling; wave energy converter; indicator; utilisation potential; data science.

Reference to this paper should be made as follows: Chakraborty, T., Majumder, M. and Khare, A. (2019) 'Application of AHP-VIKOR and GMDH framework to develop an indicator to identify utilisation potential of wave energy converter with respect to location', Int. J. Spatio-Temporal Data Science, Vol. 1, No. 1, pp.98-113.

Biographical notes: Tilottama Chakraborty is working as an Assistant Professor in the Hydro-Informatics Engineering in National Institute of Technology, Tripura Agartala, India. She passed her BTech in Electrical Engineering from the WBUT, West Bengal in 2008, ME in Water Resources and Hydraulics Engineering from the Jadavpur University, West Bengal in 2010 and pursuing her $\mathrm{PhD}$ from the National Institute of Technology, Tripura Agartala. She is working in the field of renewable energy, decision making method, soft computing and polynomial neural network. 


\begin{abstract}
Mrinmoy Majumder is working as an Assistant Professor in the Hydro-Informatics Engineering in National Institute of Technology, Tripura Agartala, India. He passed his BE in Electrical Engineering from the Biju Patnaik University of Technology, Odisha in 2003, ME in Water Resources and Hydraulics Engineering from the Jadavpur University, West Bengal in 2005 and $\mathrm{PhD}$ from the Jadavpur University in 2010. His areas of interest are water based renewable energy resources, hydro informatics engineering, nature inspired optimisation algorithms, climate change and natural resource management, soft computing, neural network and decision science.
\end{abstract}

Ankit Khare is currently working as an Assistant Professor in the Mechanical Engineering Department in Gandhi Institute for Education and Technology, Baniatangi, Bhubaneswar. He passed his BE in Mechanical Engineering from the Kali Charan Nigam Institute of Technology, UP in 2015 and ME in Hydro-Informatics Engineering from the National Institute of Technology, Agartala in 2017.

This paper is a revised and expanded version of a paper entitled 'Application of AHP-VIKOR and GMDH framework to develop an indicator to identify utilization potential of Wave energy converter with respect to location' presented at Smart Technologies in Computer and Communication (SmartTech-2017), Amity University Rajasthan, Jaipur, India, 27-29 March 2017.

\title{
1 Introduction
}

With the increasing population and development of technology, the demand for energy supply has also increased. Consequently, energy scarcity has been observed worldwide. In this aspect, ocean wave is becoming a large potential alternative energy source.

The energy of wave can be extracted by means of properly designed devices known as wave energy converter. Currently, several types of wave energy converters are being used; the reviews of these converters have been published in book form, as conference and journal papers, and as reports (Falcao, 2010).

There is approximately $8,000-80,000 \mathrm{TWh} / \mathrm{yr}$ or $1-10 \mathrm{TW}$ of wave energy in the entire ocean (Vining and Muetze, 2007). Maharashtra has a wave energy potential of $21.95 \mathrm{KW} / \mathrm{m}$ with oscillating water column (OWC) technology, Kerala has $25.08 \mathrm{KW} / \mathrm{m}$ with OWC technology, Tamil Nadu has $23.39 \mathrm{KW} / \mathrm{m}$ with hybrid wind and wave energy and $10.59 \mathrm{KW} / \mathrm{m}$ with offshore breakwater plus OWC, and Andhra Pradesh has $14.96 \mathrm{KW} / \mathrm{m}$ with the overtopping type converter (CRISIL Risk and Infrastructure Solutions Limited and Indian Institute of Technology Madras, 2014).

With the change in the locations, there is a change in wave power resources (Mork et al., 2010) and sea state (Veigas et al., 2014), which serve as limitations in utilisation potential of wave energy. Due to extreme weather events, the converter may have low output efficiency, which may lead to low utilisation potential (Citiroglu and Okur, 2014).

Hence, the present study aims to develop a new method to estimate the utilisation potential of a converter in a location of interest. 
The selection of location for installation of wave energy converters involves the consideration of various factors that are directly related to maximum utilisation of the wave power potential. The utilisation potential also depends on the design of converters and various location-dependent factors. These two factors need to be evaluated before selecting a location for a wave converter so as to yield maximum utilisation of the available power level of the area.

Although the influence of such factors on the utilisation of converters is not equal, different parameters may affect the selection in various manners. Therefore, the significance of the parameters is also considered at the time of evaluation. Unfortunately, not much investigation is available regarding this aspect. In the last five years, there were few attempts to utilised the parameters based on their importance, and then evaluation of feasibility of locations were conducted to identify the best location for a converter.

In a study conducted by Ghosh et al. (2016), artificial neural networks (ANN) and analytical hierarchy process (AHP) multi-criteria decision-making (MCDM) were used to determine the importance of the parameters for evaluating the locations for installation of WEC. However, in this study, the impact of converters was not considered. Also, the paper (Ghosh et al., 2016) utilised the results from the literature survey and responses from the experts and stakeholders to select the parameters and rank them according to the preference of the participants and citation in the literature. But a drawback of this method of feature selection is its dependence on the number of surveyors/literature analysed. ANN also has a disadvantage since both the network topology and number of inputs have to be selected by trial and error or separately using search algorithms. The AHP method is flexible, popular and easy to use, but the rating of criteria and alternative depends on the rank of the parameter which again depends on the input from the experts/literature. This may impose biasness in the selection.

In another paper (Chakraborty and Majumder, 2017c), the same objective was attempted by three different MCDM methods: AHP, DEMATEL-VIKOR, and DEMATEL-VIKOR-NFSDSS. Although AHP was utilised earlier for the same purpose, ensemble methods like DEMATEL-VIKOR and DEMATEL-VIKOR-NSFDSS were not used previously for the present objective. The impact of WEC was included for the first time, and the PNN architecture was used to model the decision support framework. PNN was adapted from the ANN architecture, but it can self-select the number of hidden layers and inputs required for the generation of the most optimal result. Another novelty of the method was that instead of surveying the literature or experts/stakeholders, the paper used statistical chart concepts to rank the parameter as per their capability to maximise the index function. However, only utilisation potential with respect to the converters and location was analysed, and the failure probability of the same converters for the same locations was not considered. The AHP used in the study could have been updated or hybridised with other methods to improve the resultant decisions for better results.

In Chakraborty and Majumder (2017a) study, the failure probability was considered to find the most feasible location with respect to a specific type of converters. In this study, the AHP and DEMATEL were hybridised to predict the significance of the parameter. Here, the input variables were selected based on the cost and efficiency potential, which considers the impact of the parameters in increasing the cost and efficiency. Here, the dependency on an expert was omitted. Although DEMATEL was a reliable method for criteria selection, the method cannot provide the degree of selection and/or rejection. In most of the decision-making processes, the preference is not crisp but 
fuzzy. The selection also becomes biased and changes from one decision maker to another, which makes the decision inconsistent.

In another study, the authors (Chakraborty and Majumder, 2017b) tried to identify a suitable location for the installation of a specific type of converter using weighted index function of the conducive and reclusive factors of evaluation. Here, the weights indicate the significance of the parameter with respect to the present objective and were determined by the AHP, ANP, and GA. The ANP method was previously not used for such kind of objective. The GA was used in a special manner where the method was incorporated to maximise the indicator function such that the real configuration of the evaluation parameters can be identified. The GA method was used as an optimisation technique and the weights as the design variable. The benefit of this method is that it identifies the importance of the parameter in the context of yielding the maximum result. But, the result may become inconsistent as the domain of acceptance changes with the change in the MCDM method, which was used to identify the boundaries of the variation of the design parameters.

AHP was also used in another study (Chakraborty and Majumder, 2017a) individually to identify the significance of the parameter without considering multiple methods and concluding to propose uniform practices during the evaluation of the evaluating factors. Although the AHP is popular for its flexibility and ease of use, it has been found to fail to identify fuzziness and select a parameter based on degrees, which results in a quick but often unreliable decision.

Given this background, the present investigation has attempted to find the significance of the evaluation factors with respect to a converter to be installed in a location. The study used hybrid MCDM methods and the AHP method. The advantage of AHP was used to compensate the disadvantage of the other methods and vice-versa. The modelling framework was developed by the PNN model. The parameters were selected by the cost and efficiency potential only. The parameters that affect the design of the converters and changes with variation in location were preferred. The GA method was not used so as to avoid the problem of boundary selection.

\subsection{Organisation of the paper}

The significance and the utilisation potential of the evaluating factors and the location were determined for optimal selection of location feasibility to yield maximum utilisation of available wave power in the area concerned.

Section 2 describes the related literature published in different journals and reports to substantiate the findings as well as identify the real problem behind the commotion.

Section 3 describes the different control charts, MCDM and PNN methods utilised to accomplice the objective of the study. The strength, weakness, and related application were also depicted in the same section as well as the previous section (Section 2).

Section 4 highlights the methodology adopted to use the advantages of the new method to accomplish the study objective. In this section the method of selection of criteria, alternatives, ranking of the alternatives by control chart method, development of the indicator function, and the validation procedure followed by the description of the case study was depicted.

Section 5 emphasises the important results that show the significance of the priority parameters as determined by the charts and consequently by the new ensemble MCDM 
method. The results from the PNN model were also depicted in this section. The models of different configurations but having the same objective were also compared, and the results are shown in this section.

In the end, the suppositions provide the conclusion that was made by the decision from the results was accentuated. The best parameters were selected by the best method of MCDM and PNN models, which were selected from the set of models with different configurations but same aspirations.

\section{Literature review}

The conventional methods of location selection include experience, check list method (Shao and Fu, 2015), analysis of different relevant criteria (Bhonsle and Junghare, 2015), and origin to distance estimation method or maximal covering location method (Kofoed et al., 2006; Flower and Knott, 1980). In recent years, most of the location selection methods employ MCDM methods to objectively identify the suitable location by comparing the option with respect to different criteria and sub criteria.

Renewable energy will play an important role in the future society of the 21 st century. It needs to be used carefully and planned in an optimum location to provide economic growth and development. A combination of fuzzy logic, weighted linear combination (WLC) and MCDM was applied to locate the optimal solar sites (Zoghi et al., 2017a). With the help of ANN and MCDM techniques, a location suitability index has been formed to identify the best location (Zoghi et al., 2017). Classified data and GIS Offshore wind farm site selection study have been utilised (Taehyun et al., 2016).

Site selection of hybrid offshore wind and wave energy systems (HOWiWaES) has been assessed by the framework, which is based on the combined use of multi-criteria decision-making methods and geographical information systems (GIS) (Vasileiou et al., 2017). ANN and AHP MCDM were used to find the importance of the parameters required to evaluate the locations for installation of WEC (Benedicenti, 2016). Optimum locations for co-located wave and wind energy farms were derived using the co-location feasibility (CLF) index (Astariz and Iglesias, 2016). Identification of sites for offshore energy platforms has been done using GIS and MCDM methods (Cradden et al., 2016).

The renewable electricity generation technologies were assessed against a range of sustainability indicators (Evans et al., 2009). To identify the suitable sites for co-located wave and wind farms, the study developed a new approach based on an ad hoc tool, the CLF index, and a joint characterisation of the wave and wind (Astariz and Iglesias, 2016). An analytical tool has been used for assessing current energy production and use patterns at a national level (Vera and Langlois, 2007).

Energy planning has become complex due to the involvement of multiple benchmarks like technical, social, economic, and environmental. In such situation, multiple criteria decision-making (MCDM) plays a vital role in designing such systems by considering various criteria and objectives (Kumar et al., 2017). The fuzzy MCDM model combines AHP based on interval type-two fuzzy sets, and hesitant fuzzy TOPSIS methods were used to evaluate renewable energy alternatives for Turkey (Çolak and Kaya, 2017a). An MCDM approach is applied using the decision-making trial and evaluation laboratory model (DEMATEL) technique, integrated with analytic network process (ANP), for selecting the most appropriate renewable energy resource in Turkey (Çolak and Kaya, 2017b). 
Polynomial neural networks (PNNs) provide an efficient, general interpolation method for nonlinear functions of several variables and are applied in potential energy surfaces study (Blank et al., 1995). The outcomes related to wind energy, solar energy, geothermal energy, hydro energy, ocean energy, bioenergy, hydrogen energy, and hybrid energy have been summarised (Jha et al., 2017). To estimate hourly values of the diffuse solar-radiation at the surface in São Paulo City, Brazil, a perceptron neural-network technique was applied (Soares et al., 2004). A group method of data handling (GMDH) in conjunction with PNN was used to quantify uncertain natural frequency for laminated composite plates by using a novel surrogate model (Dey et al., 2016). The hybrid model integrates a polynomial fitting method, and an ANN model is used to estimate the coefficient of performance in an absorption intermittent cooling system (Escobedo-Trujillo et al., 2016).

\section{Methods applied}

The objective was accomplished by the adaptation of a two-step methodology. In the first step, MCDM was used to estimate the priority values of the factors relevant to the wave energy converter. In the second step, the same priority values were used to develop the model to identify the suitable converter for a location. In this regard, GMDH and multi-linear regression analysis (MLR) were used.

An integrated AHP-rough number based compromise ranking method (also known as VIKOR) was used to estimate the most significant parameters relevant to identify the ideal converter for wave power generation.

Four most important parameters were considered for the development of the model.

- AHP: the AHP was originally devised by Saaty (1980) to provide a framework for solving different types of multi-criterion decision problems. In this method, the problem is broken down into its constituent elements with the best alternative usually being selected by making comparisons between alternatives with respect to each attribute.

Therefore, the AHP can be considered as both a descriptive tool and a prescriptive model for decision making. Additionally, one of the major advantages of AHP is that it calculates the inconsistency criteria as a ratio of the decision maker's inconsistency and randomly generated criteria. Although a higher value of inconsistency criteria requires a revaluation of pair wise comparisons, decisions obtained in certain cases can also be taken as the best alternative. AHP is widely used for decision-making problems like evaluation of renewable energy project (Malik et al., 2014), energy-aware decision-making (Benedicenti, 2016), project quality evaluation in construction engineering (Shao and $\mathrm{Fu}, 2015$ ), power system (Bhonsle and Junghare, 2015), and wind energy (Mogre et al., 2016).

- VIKOR: VIKOR was developed by Opricovic (1998) and Opricovic and Tzeng (2002) for multi-criteria optimisation of complex systems, and it focus on ranking and selecting from a set of alternatives. This method determines compromised solutions for a problem with conflicting criteria, which can help the decision makers to reach a final decision. The compromised ranking method of VIKOR consists of several steps (Chakraborty and Majumder, 2017c). The various J alternatives are 
denoted as $\mathrm{a}_{1}, \mathrm{a}_{2}, \ldots, \mathrm{a}_{\mathrm{J}}$. For alternative $\mathrm{a}_{\mathrm{j}}$, the rating of the $\mathrm{i}^{\text {th }}$ aspect is denoted by $\mathrm{f}_{\mathrm{ij}}$, i.e., $f_{i j}$ is the value of $i^{\text {th }}$ criterion function for the alternative $a_{j} ; n$ is the number of criteria. The method is applied in evaluating the performance of Iranian cement firms (Rezaie et al., 2014), multi-criteria renewable energy project (Kaya and Kahraman, 2010), and risk evaluation in failure mood (Liu et al., 2012).

Though AHP is the most commonly used method, it may give incorrect representation of importance when comparing two similarly important variables. Thus, to mitigate this issue, the VIKOR-MCDM method was integrated with AHP to consider the relationship between the alternatives and objective of the decisionmaking problem.

- GMDH neural network: the GMDH is a self-organising technique based on the iterative processing of a sequence of operations (Mrugalski et al., 2002). Its functions are similar to that of the neurons found in nature. It consists of a series of interconnected algorithms that provide a 'hidden' interim network mapping input data into output. As in a biological neuron, signals are only transmitted when the inputs reach a certain threshold after which the impulses are carried on to the next neuron. In a similar way, data inputs into the ANN networks are passed on from one 'hidden' interim layer to the next based on how significant they are to achieving a set of goals or criteria. This method can provide a great insight into gauging the impact of a given parameter on the overall likelihood of attaining a goal or specified criteria. A GMDH model with multiple inputs and one output is a subset of components of the base function [equation (1)].

$$
Y\left(x_{1}, \ldots \ldots, x_{n}\right)=a_{0}+\sum_{1}^{m=i} a_{1} f_{i}
$$

where $f$ is an elementary function dependent on different sets of inputs, a refers to the coefficients, and $\mathrm{m}$ is the number of the base function components.

GMDH has been applied in various studies such as compressive strength of concrete based on absorbed extraterrestrial solar radiations (Najafzadeh and Tafarojnoruz, 2016), prediction of discharge rate and water quality (Kewalramani and Gupta, 2016), identification of failure probability of wave energy converter (Chakraborty and Majumder, 2017a), and short-term wind speed forecasting (Kaur et al., 2016).

- MLR: this is a statistical analysis that allows examining how multiple independent variables are related to a dependent variable. Once this relation is identified, information about all of the independent variables can be used to make more powerful and accurate predictions about why things are the way they are.

A MLR analysis software but non cognitive method, MaxStat has been used in the present study.

\section{Detailed methodology}

At first, the factors (Table 1) were categorised into two categories. The parameters that change with the location were placed under 'location' category, whereas the factors 
related to design of converters or changes with different types of converters were kept under the 'Design' category.

Table 1 Selected parameters for the present study objective

\begin{tabular}{lc}
\hline & Name of the parameters \\
\hline Locational & Significant wave height $\left(\mathrm{W}_{1}\right)$ \\
aspects & Wave amplitude $\left(\mathrm{W}_{2}\right)$ \\
Wave period $\left(\mathrm{W}_{3}\right)$ & \\
Depth of the ocean $\left(\mathrm{W}_{4}\right)$ \\
Shipping density $\left(\mathrm{W}_{5}\right)$ \\
Percentage of regular waves $\left(\mathrm{W}_{6}\right)$ \\
Direction of wave $\left(\mathrm{W}_{7}\right)$ \\
Average wave power level of the sea $\left(\mathrm{W}_{8}\right)$ \\
Corrosion $\left(\mathrm{W}_{9}\right)$ \\
Survivability $\left(\mathrm{W}_{10}\right)$ \\
Design aspects \\
Size and shape (diameter, draft, displacement, stroke length, height $)\left(\mathrm{W}_{11}\right)$ \\
Mass of the Buoy $\left(\mathrm{W}_{12}\right)$ \\
Thickness of the material used $\left(\mathrm{W}_{13}\right)$ \\
Efficiency of wave rotor/generator $\left(\mathrm{W}_{14}\right)$ \\
Efficiency of turbine $\left(\mathrm{W}_{15}\right)$ \\
Efficiency of energy storage system $\left(\mathrm{W}_{16}\right)$ \\
Efficiency of hydraulic system $\left(\mathrm{W}_{17}\right)$ \\
Power conversion efficiency at constant or nearly constant RPM $\left(\mathrm{W}_{18}\right)$ \\
\hline
\end{tabular}

Figure 1 Location map for the present study objective (see online version for colours)

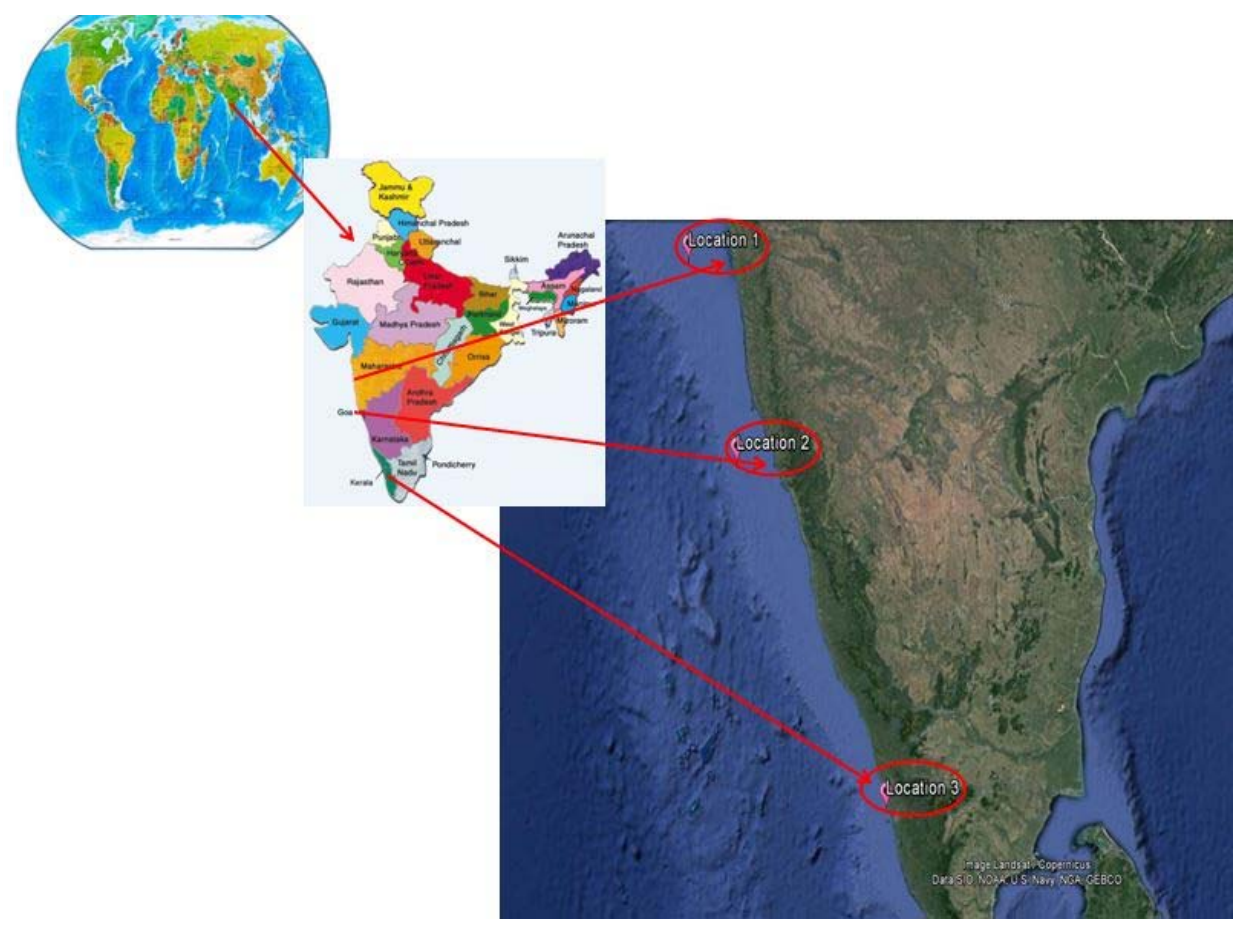


After the factors were selected and grouped as per the categories, the next step was to find the priority values of the parameters with the help of the MCDM method. This method involves two steps: selection of criteria and selection of alternatives. In the present investigation, the criteria and alternatives were selected based on the citation frequency in the relevant literature. After the factors were selected, they were ranked with the systemic literature review followed by a group of experts.

Location and design were used as the criteria with respect to which the alternatives were compared. The MCDM method was used to find the priority values of all the alternatives. The ranks of the alternatives as derived from the ranking methods were used while comparing them with respect to the criteria. The hierarchy structure of MCDM method is shown in Figure 2.

Figure 2 Hierarchy structure of MCDM method (see online version for colours)

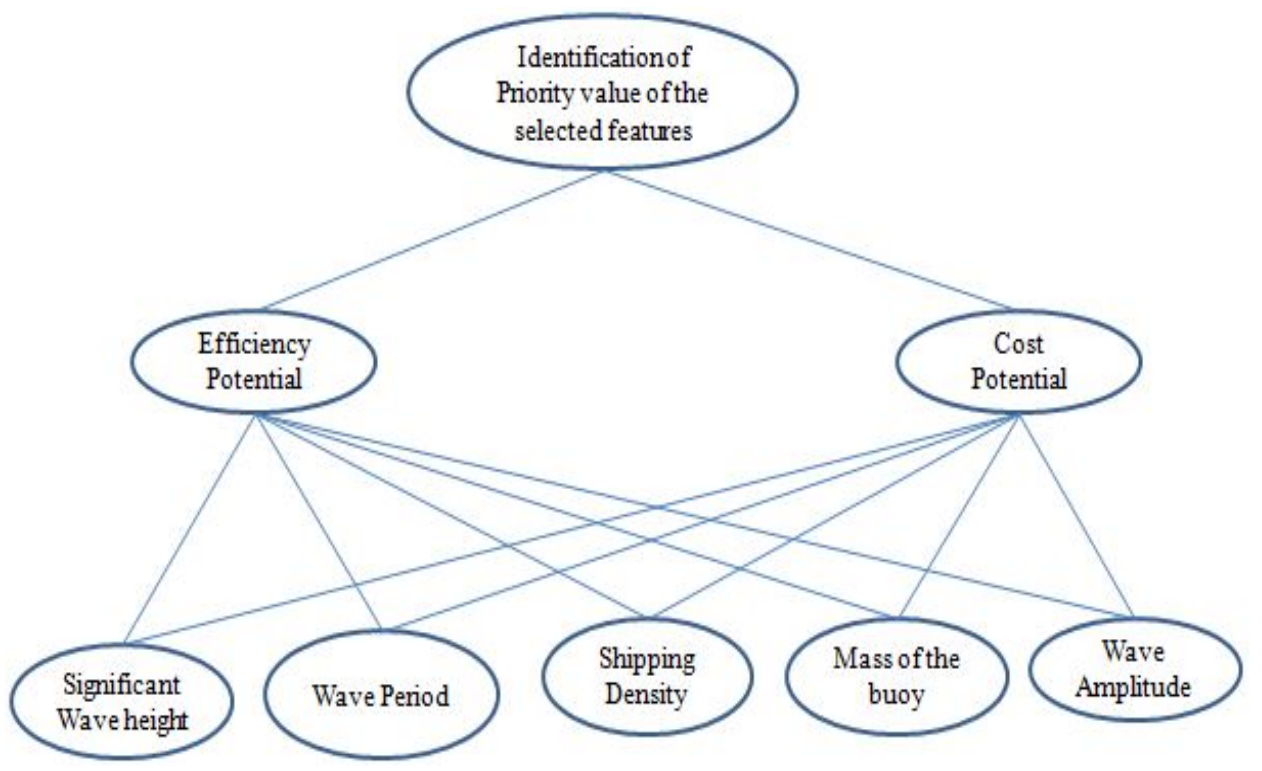

The GMDH (Kewalramani and Gupta, 2016) and MLR were used as the predictive method for developing the model in the present study, which estimates the actual output from a converter with respect to its operation efficiency and location impacts.

\subsection{Selection of criteria}

1 Efficiency potential: the commonly used equation for calculating the power potential, as proposed by Chakraborty and Majumder (2017a), is given in equation (2).

$$
P w=\frac{p g^{2}}{64 \pi} T_{e} H_{s}^{2}
$$

where $P_{w}=$ average wave power; $H_{s}^{2}=$ significant wave height; $T_{e}=$ peak period; $\rho=$ density of water; and $g=$ acceleration due to gravity. 
As $H_{s}$ squared is directly proportional to $P_{w}$, the efficiency potential or location with a high magnitude wave height will have a higher level of conversion efficiency. The relative score was calculated by equation (3).

$$
R S=\left(\frac{R}{\operatorname{Max} R}\right)^{-1}
$$

where $R=1,2, \ldots \ldots, 7 ; \operatorname{Max}(R)=7$.

2 Cost potential: the cost potential of parameters depends on the proportionality of the parameter to the mooring cost or the cost required to hold the converters in place.

The score of the parameters for the cost potential was calculated by equation (4). Here, if $\Delta C$ is the difference in cost for two different locations and $\Delta H s$ is the change in the wave height, then the cost potential of wave height can be represented by equation (5).

$$
\begin{gathered}
C=\frac{\Delta C}{\Delta H} \\
C=\frac{\Delta C}{\Delta P}
\end{gathered}
$$

The general equation for the estimation of cost potential for the parameter is depicted in equation (4).

where $\Delta P$ is the change in the magnitude of the parameter with respect to locations.

\subsection{Selection of alternatives}

Eighteen different alternatives (Table 1), based on location and design factor, were selected for the present investigation from the survey of the literature and experts.

\subsection{Development of the model}

The inputs to the model were the four most important parameters and the average wave power $\left(P_{w}\right)$. The model output was the value which is the ratio of actual output $(\mathrm{AO})$ and four most important parameters with the average wave power. The output value was calculated with the help of equations (6) and (7).

$$
\begin{aligned}
& \text { Model output }=\frac{\text { Actual output }}{P_{1}+P_{2}+P_{3}+P_{4}+P_{w}} \\
& \text { Actual output }=C E X P_{w}
\end{aligned}
$$

where $C E=$ converter efficiency (Evans et al., 2009; Vera and Langlois, 2007); $P_{w}=$ average wave power; $P_{1}, P_{2}, P_{3}$ and $P_{4}$ are the four most important parameters.

Two models, i.e., GMDH-based neural network and multiple linear regression analysis model (MaxStat), were developed to identify the relationship between the inputs and the output. 
The performance of the two models was analysed by mean absolute error (MAE) (Irurzun et al., 2013), PBIAS (Moriasi et al., 2007), correlation (R) (Moriasi et al., 2007), MRE (Hyndman and Koehler, 2006) and RMSE (Willmott and Matsuura, 2005). An equivalent performance index (EPI) was prepared to represent the performance of the models [equation (7)]. The model output is directly proportional to model efficiency.

$$
\begin{aligned}
E P I & =\left\{\frac{R_{t s}}{M A E_{t s}+M R E_{t s}+R M S E_{t s}+P B I A S_{t s}} * 0.6\right\} \\
& +\left\{\frac{R_{t r}}{M A E_{t r}+M R E_{t r}+R M S E_{t r}+P B I A S_{t r}} * 0.4\right\}
\end{aligned}
$$

where $I t_{s}=$ Model output value for the testing model; $I t_{r}=$ model output value for the training model.

Two steps were involved in the calculation of EPI. In the first step, the values of MAE, PBIAS, correlation (R), MRE and RMSE for both the testing and training phases were calculated for each model. In the second step, the EPI were calculated for each model. As the model is directly proportional to the EPI value, so the maximum EPI shows the best model among the two developed model.

\subsection{Case study}

The maximum utilisation probability of two converters, Pelamis (Henderson, 2006) and SearveG3 (Cordonnier et al., 2015), were analysed for three different location. The wave power potential (Table 2) in three different locations (Figure 1) was also calculated using the wave power potential equation (Liu et al., 2012) and the model results.

\begin{tabular}{|c|c|c|}
\hline \multicolumn{2}{|c|}{ Location } & \multirow{2}{*}{ Power potential $\mathrm{KW} / \mathrm{m}$} \\
\hline Lat/long & Nearer costal region & \\
\hline Location-1 $\left(18.05^{\circ} \mathrm{N}, 72.5^{\circ} \mathrm{E}\right)$ & Mumbai & 11.81 \\
\hline Location-2 $\left(15.5^{\circ} \mathrm{N}, 73.5^{\circ} \mathrm{E}\right)$ & Agonda & 15.895 \\
\hline Location-3 $\left(10.05^{\circ} \mathrm{N}, 76.5^{\circ} \mathrm{E}\right)$ & Kerala & 20.00 \\
\hline
\end{tabular}

Table 2 The wave power potential of three locations

\section{$5 \quad$ Results and discussions}

a Rank of the selected factors: the ranking as per the MCDM methods are shown in Table 3.

According to Table 3, significant wave height, wave amplitude, wave period and mass of the Buoy are the four most important parameters.

b EPI value: training and testing results with the EPI value of the developed model by GMDH and multiple linear regression are shown in Table 4 and Table 5, respectively.

The EPI value shows that the model developed by GMDH is the best between the two models. 
Table 3 Rank of the parameter according to the MCDM method

\begin{tabular}{lccc}
\hline Name of the parameters & AHP-VIKOR & AHP & VIKOR \\
\hline Significant wave height & 1 & 1 & 1 \\
Wave amplitude & 2 & 2 & 2 \\
Wave period & 3 & 3 & 3 \\
Depth of the ocean & 12 & 12 & 12 \\
Shipping density & 5 & 5 & 5 \\
Percentage of regular waves & 6 & 6 & 6 \\
Direction of wave & 7 & 7 & 7 \\
Average wave power level of the sea & 13 & 15 & 13 \\
Corrosion & 15 & 13 & 15 \\
Survivability & 16 & 16 & 16 \\
Size and shape (diameter, draft, displacement, & 17 & 17 & 17 \\
stroke length, height) & & & \\
Mass of the Buoy & 4 & 4 & 4 \\
Thickness of the material used & 18 & 18 & 18 \\
Efficiency of wave rotor/generator & 8 & 8 & 8 \\
Efficiency of turbine & 9 & 9 & 10 \\
Efficiency of energy storage system & 10 & 10 & 9 \\
Efficiency of hydraulic system & 11 & 11 & 11 \\
Power conversion efficiency at constant or & 13 & 13 & 13 \\
nearly constant RPM & & & \\
\hline
\end{tabular}

Table 4 Training and testing results of the developed model by GMDH

\begin{tabular}{lccc}
\hline & Training & Testing & EPI \\
\hline PBIAS & $6.79079^{-13}$ & 0.226655 & $2.26383^{25}$ \\
MRE & $1.78402^{-08}$ & $7.01547^{-08}$ & \\
MAE & 0.001492 & 0.0014374 & \\
RMSE & 0.0024392 & 0.0020570 & \\
CORRELATION & 0.997964 & 0.998644 & \\
\hline
\end{tabular}

Table 5 Training and testing results of the developed model by MLR

\begin{tabular}{lccc}
\hline & Training & Testing & EPI \\
\hline PBIAS & 5.8909172 & 3.589632 & 0.194657206 \\
MRE & $3.66111^{-05}$ & $2.65431^{-05}$ & \\
MAE & 0.0092992 & 0.0078925 & \\
RMSE & 0.5461574 & 0.7546213 & \\
CORRELATION & 0.9470806 & 0.9857065 & \\
\hline
\end{tabular}


Figure 3 Model output for three different locations predicted by the GMDH value (see online version for colours)

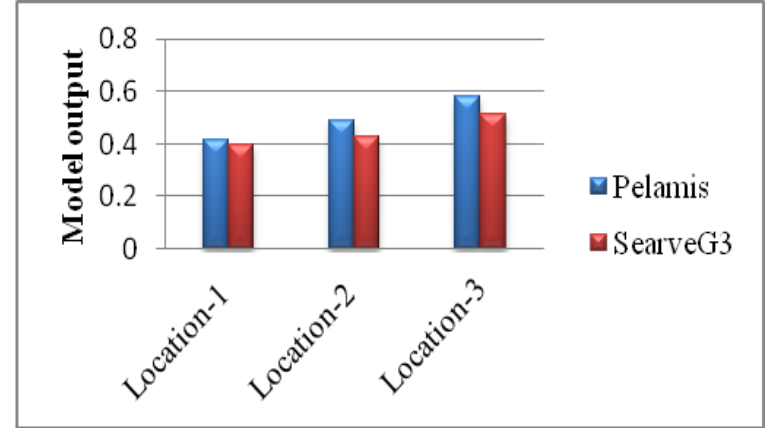

It can be seen from Figure 3 that Location-3 has the highest potential for installing the Pelamis converter and convert it to the most suitable converter. It has also been observed that the Pelamis converter has higher efficiency potential than SearveG3 for each location. As per the power potential of the three selected locations, Location 3 has the highest power potential. It shows model accuracy in terms of identification of highest potential location.

\section{Conclusions}

The present study attempts to develop a new method, which represents the utilisation potential of the converters in a specific location. This model is made objective by the application of MCDM and cognitive with the help of GMDH and MLR. The best model was identified from two different models having the same inputs and output. The model with the highest efficiency was found to have a correlation value of 0.9979 , which shows the reliability of the model. As per the case studies, Location-3 (Kerala) has the highest utilisation potential with Pelamis wave energy converter.

Although the model has the potential to become a tool with which engineers can easily identify the ideal wave energy converters in specific locations, this method has some limitations. The importance of the variables was estimated by one single hybrid MCDM method, but this may change if other MCDM methods are used. This shows that the model is dependent on the type of methods utilised to find the priority value of the parameters. These drawbacks can be mitigated if some uniform policies are adopted regarding the selection of method, criteria, and alternatives while the indicator is implemented in a decision support system. 


\section{References}

Astariz, S. and Iglesias, G. (2016) 'Selecting optimum locations for co-located wave and wind energy farms. Part I: the co-location feasibility index', Energy Conversion and Management, Vol. 122, pp.589-598.

Benedicenti, L. (2016) 'AHP and soft computing for energy-aware decision-making', 30th Int. Conf. Adv. Inf. Netw. Appl. Work., pp.273-275.

Bhonsle, J.S. and Junghare, A.S. (2015) 'Application of MCDM - AHP technique for PMU placement in power system', IEEE International Conference on Computational Intelligence \& Communication Technology (CICT), pp.513-517.

Blank, T.B., Brown, S.D, Calhoun, A.W. and Doren, D.J. (1995) 'Neural network models of potential energy surfaces', The Journal of chemical physics, Vol. 103, No. 10, pp.4129-4137.

Chakraborty, T. and Majumder M. (2017a) 'Application of AHP-DEMATEL and GMDH framework to develop an indicator to identify failure probability of wave energy converter', Indian Journal of Science and Technology, Vol. 10, No. 31, pp.1-6.

Chakraborty, T. and Majumder, M. (2017b) 'Application of non-parametric and cognitive modelling for development of location selection indicator for wave energy converters', International Journal of Control Theory and Application, Vol. 10, No. 6, pp.109-118.

Chakraborty, T. and Majumder, M. (2017c) 'Application of statistical charts, multi-criteria decision making and polynomial neural networks in monitoring energy utilization of wave energy converters', Environment, Development and Sustainability, pp.1-21.

Citiroglu, H.K. and Okur, A. (2014) 'An approach to wave energy converter applications in Eregli on the western black sea coast of Turkey', Applied Energy, Vol. 135, pp.738-747.

Çolak, M, and Kaya, İ. (2017a) 'Prioritization of renewable energy alternatives by using an integrated fuzzy MCDM model: a real case application for Turkey', Renewable and Sustainable Energy Reviews, Vol. 80, pp.840-853.

Çolak, M, and Kaya, İ. (2017b) 'Prioritization of renewable energy alternatives by using an integrated fuzzy MCDM model: a real case application for Turkey', Renewable and Sustainable Energy Reviews, Vol. 80, pp.840-853.

Cordonnier, J., Gorintina, F., De Cagny, A., Clement, A.H. and Babarit, A. (2015) 'SEAREV: case study of the development of a wave energy converter', Renewable Energy, Vol. 80, pp.40-52.

Cradden, L., Kalogeri, C., Martinez Barrios, I., Galanis, G., Ingram, D. and Kallos, G. (2016) 'Multi-criteria site selection for offshore renewable energy platforms', Renewable Energy, Vol. 87, pp.791-806.

CRISIL Risk and Infrastructure Solutions Limited and Indian Institute of Technology Madras (2014) Study on Tidal \& Waves Energy in India: Survey on the Potential \& Proposition of a Roadmap, Indian Institute of Technology Madras, 31 December 2014.

Dey, S., Naskar, S., Mukhopadhyay, T., Gohs, U., Spickenheuer, A., Bittrich, L., Sriramula, S., Adhikari, S. and Heinrich, G. (2016) 'Uncertain natural frequency analysis of composite plates including effect of noise - a polynomial neural network approach', Composite Structures, Vol. 143, pp.130-142.

Escobedo-Trujillo, B.A., Colorado, D., Rivera, W. and Alaffita-Hernandez, F.A. (2016) 'Neural network and polynomial model to improve the coefficient of performance prediction for solar intermittent refrigeration system', Solar Energy, Vol. 129, pp.28-37.

Evans, A., Strezov, V. and Evans, T.J. (2009) 'Assessment of sustainability indicators for renewable energy technologies', Renewable and Sustainable Energy Reviews', Vol. 13, No. 5, pp.1082-1088. 
Falcao, A.F.D.O. (2010) 'Wave energy utilization: a review of the technologies', Renewable and Sustainable Energy Reviews, Vol. 14, No. 3, pp.899-918.

Flower, J.O. and Knott, G.F. (1980) 'Describing-function method for estimating the performance of a dynamic system having nonlinear-power take-off, with application to wave-power conversion', Energy Convers. Manage, Vol. 20, pp.127-134.

Ghosh, S., Chakraborty, T., Saha, S. Majumder, M. and Pal, M. (2016) 'Development of the location suitability index for wave energy production by ANN and MCDM techniques', Renewable and Sustainable Energy Reviews, Vol. 59, pp.1017-1028.

Henderson, R. (2006) 'Design, simulation, and testing of a novel hydraulic power take-off system for the Pelamis wave energy converter', Renewable Energy, Vol. 2, pp.271-283.

Hyndman, R.J. and Koehler, A.B. (2006) 'Another look at measures of forecast accuracy', International Journal of Forecasting, Vol. 4, pp.679-688.

Irurzun, M.A., Chaparro, M.A.E., Sinito, A.M., Gogorza, C.S.G., Lirio, J.M., Nuñez, H., Nowaczyk, N.R. and Böhnel, H.N. (2013) 'Preliminary relative palaeointensity record and chronology on sedimentary cores from lake Esmeralda (Vega Island, Antarctica)', Latimag Letters, Vol. 6, pp.1-7.

Jha, S.K., Bilalovic, J., Jha, A., Patel, N. and Zhang, H. (2017) 'Renewable energy: present research and future scope of artificial intelligence', Renewable and Sustainable Energy Reviews, Vol. 77, pp.297-317.

Kaur, T., Kumar, S. and Segal, R. (2016) 'Application of artificial neural network for short term wind speed forecasting', in Power and Energy Systems: Towards Sustainable Energy (PESTSE), 2016 Biennial International Conference on IEEE, pp.1-5.

Kaya, T. and Kahraman, C. (2010) 'Multicriteria renewable energy planning using an integrated fuzzy VIKOR \& AHP methodology: the case of Istanbul', Energy, Vol. 35, No. 6, pp.2517-2527.

Kewalramani, M.A. and Gupta, R. (2016) 'Group method of data handling algorithms to predict compressive strength of concrete based on absorbed extraterrestrial solar radiations', Key Engineering Materials, Vol. 689, pp.108-113.

Kofoed, J.P., Frigaard, P., Friis-Madsen, E. and Sorensen, H.C. (2006) 'Prototype testing of the wave energy converter wave dragon', Renew Energy, Vol. 31, pp.181-189.

Kumar, A., Sah, B., Singh, A.R., Deng, Y., He, X., Kumar, P. and Bansal, R.C. (2017) 'A review of multi criteria decision making (MCDM) towards sustainable renewable energy development', Renewable and Sustainable Energy Reviews, Vol. 69, pp.596-609.

Liu, H-C., Liu, L., Liu, N. and Mao, L-X. (2012) 'Risk evaluation in failure mode and effects analysis with extended VIKOR method under fuzzy environment', Expert Systems with Applications, Vol. 17, pp.12926-12934.

Malik, A., Al Badi, M., Al Kahali, A., Al Nabhani, Y., Al Bahri, A., Al Barhi, H. and Khod, A. (2014) 'Evaluation of renewable energy projects using multi-criteria approach', Global Humanitarian Technology Conference (GHTC), IEEE, IEEE, pp.350-355.

Mogre, R., Talluri, S. and D'Amico, F. (2016) 'A decision framework to mitigate supply chain risks: an application in the offshore-wind industry', IEEE Transactions on Engineering Management, pp.1-10.

Moriasi, D.N., Arnold, J.G., Liew, M.W.V, Bingner, R.L., Harmel, R.D. and Veith, T.L. (2007) 'Model evaluation guidelines for systematic quantification of accuracy in watershed simulations', Transactions of the ASABE, Vol. 50, No. 3, pp.885-900.

Mork, G., Barstow, S., Kabuth, A. and Pontes, M.T. (2010) 'Assessing the global wave energy potential', in ASME 29th International Conference on Ocean, Offshore and Arctic Engineering, American Society of Mechanical Engineers, pp.447-454.

Mrugalski, M., Arinton, E. and Korbicz, J. (2002) 'Methods of neuron selection in synthesis of GMDH neural networks', in Proceedings of the 14th National Conference on Automatic Control, pp.24-27. 
Najafzadeh, M. and Tafarojnoruz, A. (2016) 'Evaluation of neuro-fuzzy GMDH-based particle swarm optimization to predict longitudinal dispersion coefficient in rivers', Environmental Earth Sciences, Vol. 75, No. 2, pp.1-12.

Opricovic, S. (1998) Multicriteria Optimization of Civil Engineering Systems, Faculty of Civil Engineering, Belgrade.

Opricovic, S. and Tzeng, G-S. (2002) 'Multicriteria planning of post-earthquake sustainable reconstruction', Computer-Aided Civil and Infrastructure Engineering, Vol. 17, No. 3, pp.211-220.

Rezaie, K., Ramiyani, S.S., Nazari-Shirkouhi, S. and Badizadeh, A. (2014) 'Evaluating performance of Iranian cement firms using an integrated fuzzy AHP-VIKOR method', Applied Mathematical Modelling, Vol. 38, No. 21, pp.5033-5046.

Saaty, T.L. (1980) The Analytic Hierarchy Process, Planning, Priority Setting, Resource Allocation, Mc-Graw Hill, New York, USA.

Shao, H. and Fu, H. (2015) 'Construction engineering project quality evaluation method based on fuzzy analytic hierarchy process', Int. Conf. Intell. Transp. Big Data Smart City, Vol. 2, pp.228-231.

Soares, J., Oliveira, A.P., Boznar, M.Z., Mlakar, P., Escobedo, J.F. and Machado, A.J. (2004) 'Modeling hourly diffuse solar-radiation in the city of São Paulo using a neural-network technique', Applied Energy, Vol. 79, No. 2, pp.201-214.

Taehyun, K., Park, J. and Maeng, J. (2016) 'Offshore wind farm site selection study around Jeju Island, South Korea', Renewable Energy, Vol. 94, pp.619-628.

Vasileiou, M., Loukogeorgaki, E. and Vagiona, D.G. (2017) 'GIS-based multi-criteria decision analysis for site selection of hybrid offshore wind and wave energy systems in Greece', Renewable and Sustainable Energy Reviews, Vol. 73, pp.745-757.

Veigas, M., López, M. and Iglesias, G. (2014) 'Assessing the optimal location for a shoreline wave energy converter', Applied Energy, Vol. 132, pp.404-411.

Vera, I. and Langlois, L. (2007) 'Energy indicators for sustainable development', Energy, Vol. 32, No. 6, pp.875-882.

Vining, J.G. and Muetze, A. (2007) 'Governmental regulation of ocean wave energy converter installations', in Industry Applications Conference, 42nd IAS Annual Meeting, Conference Record of the IEEE, pp.749-755.

Willmott, C.J. and Matsuura, K. (2005) 'Advantages of the mean absolute error (MAE) over the root mean square error (RMSE) in assessing average model performance', Climate Research, Vol. 1, pp.79-82.

Zoghi, M., Ehsani, A.H., Sadat, M., Amiri, M.J. and Karimi, S. (2017) 'Optimization solar site selection by fuzzy logic model and weighted linear combination method in arid and semi-arid region: a case study Isfahan-IRAN', Renewable and Sustainable Energy Reviews, Vol. 68, pp.986-996. 